\title{
Pressurized housings, standardizing possibilities, opportunities and difficulties
}

\author{
Gabriela Pupăzan ${ }^{1 *}$, Cosmin Colda ${ }^{1}$, Tiberiu Csaszar $^{1}$, Adriana Andriș ${ }^{1}$, and Dănuț Grecea ${ }^{1}$ \\ ${ }^{1}$ National Institute for Research and Development in Mine Safety and Protection to Explosion - \\ INSEMEX, 32-34 G-ral Vasile Milea Street, Petrosani, ROMANIA
}

\begin{abstract}
Explosive atmospheres can be caused by gases, vapours, mists, dust, lint or fibres of flammable substance. If enough substance and air are mixed, the imminence of an explosion depends on probability and efficiency of the ignition source. Hazardous areas classified in sectors must be protected from ignition sources. Equipment and protective systems intended for use in potentially explosive atmospheres should be selected to meet the appropriate requirements for protective equipment and systems. The current paper aims to identify opportunities for standardization of pressurized equipment. The first part of the paper presents the risk of explosion associated with the presence of flammable substances and protection against explosions. The concept and opportunities of using pressurization are described in the second part of the paper. The third part refers to considerations regarding size and shape of pressurized equipment. A synthesis of pressurized equipment's offer - dimensions, shape and functional role, is presented in the last part of the paper. Among the conclusions the existence of a gauge profile that depends on purpose, volume, operating position and assembly of the equipment, was mentioned.
\end{abstract}

\section{Risk of explosion}

Explosion hazards may occur in all activities involving flammable substances which, when mixed with air, may form an explosive atmosphere and may include many of the raw materials, intermediates and wastes from production processes. Virtually, all economy branches are affected by dangers posed by explosive atmospheres, which occur in a wide range of processes and operations $[1,2]$.

As explosions can cause human and material losses, assessment of explosion risk and establishment of appropriate measures to reduce it to acceptable levels, in accordance with rules and standards in force (NEx01-06 / 2007 and GD 1058/2006) [3] is of particular importance for safety and health of people and property.

Occurrence of various types of protection was determined by critical situations regarding safety regime when operating technical equipment in spaces with explosive atmosphere but also by forecast of imminent technical advances.

\footnotetext{
*Corresponding author: gabriela.pupazan@insemex.ro
} 
An essential element in assessing the risk of explosions in workplaces where explosive atmospheres may occur is represented by personal protective equipment and installations which must be designed, manufactured, installed and maintained in a manner that cannot generate ignition sources.

The risk of explosion occurs when the following conditions are met, simultaneously: presence of an oxidant such as oxygen in the air, presence of a flammable substance (gas, vapor, dust or powders) and presence of an ignition source, which may be a source of energy strong enough to ignite fuel (flame, electrical / mechanical spark, a high temperature surface, etc.).

Assessment and testing of equipment representing part of an explosion-proof system [4], for certification, shall take into account the risk of explosions which must be minimized in order to ensure safety and health of human life and to prevent damage of goods and last, but not least, to prevent damage to the environment.

In order to prevent the risk of explosion in areas with explosive atmospheres, it is essential to have certified equipment, prepared for this purpose.

All equipment, part of an explosion-proof system, used in potentially explosive atmospheres, shall meet the following requirements:

- be adequately protected from explosion;

- maintain the level of protection for environmental conditions for which they were built;

- be able to withstand all (foreseeable) stresses to which they are subjected during storage, transport, installation and operation of the system.

Explosion risk attendance, in accordance with the ATEX Directive 2014/34 / EU [5] transposed into national legislation by GD 1058/2006, involves technical and organizational implementation of the following steps: preventing the occurrence of explosive atmospheres by using ventilation and monitoring systems; preventing ignition of explosive atmospheres by using explosion proof equipment and preventing the aggravation of explosions' consequences by using protective systems.

\section{Explosion protection}

Explosion protection is of particular importance for safety, as explosions endanger life and health of workers due to uncontrolled effects of flames and pressure, presence of harmful reaction products and consumption of oxygen in the ambient air breathed by workers.

Explosion protection has the role of preventing ignition of explosive atmospheres, i.e., prevention of potential sources of ignition and limiting the occurrence of explosive atmospheres through protection measures (isolation, suppression and constructive limitation).

The protection measures aim at reducing, to an acceptable level, the probability that technical equipment (electrical and non-electrical) will become a source of initiation.

When electrical equipment is to be installed in areas where dangerous concentrations and amounts of flammable gases, vapours, mists or dusts may be present in the atmosphere, protective measures shall be applied to reduce the likelihood of an explosion caused by electric arc ignition, sparks or hot surfaces produced either during normal operation or under specific fault conditions.

In order to obtain effective explosion protection against uncontrolled, unintended explosions associated with disastrous consequences, it is necessary to eliminate one of the three factors mentioned above, namely the sources of initiation from potentially explosive atmospheres. This factor effectively prevents explosions, because the other two factors oxygen in the air and, often, the flammable substance - cannot be reliably and permanently excluded from workplaces. 
Explosion protection of pressurized equipment in accordance with the specific standard [6] is carried out by means of a shielding gas, maintained at a pressure above the pressure of outside atmosphere and used for preventing the occurrence of an explosive atmosphere of gas or dust inside the housings, which may or may not contain an internal source of flammable gas or flammable vapours.

Pressurization protection is only justified if it is coordinated with extraction of heat from energy losses of the installed electrical equipment. An enclosure that needs explosion protection is purged with inert gas. This creates an overpressure that is maintained during the operation of the pressurized system. This overpressure prevents the penetration of explosive gases and vapours from the environment (pressurization with loss compensation).

Pressurization protection [6] is divided into three types of pressurization: pxb, pyb and pzc. These types are chosen according to the outside explosive atmosphere (Group I, Zone 1 or Zone 2), to the possibility of an internal release and to the possibility that the equipment inside the pressurized housing produces ignition or is protected by another type of protection, with a protection level lower than the application requirement.

The presence of explosive atmospheres and at the same time, the presence of an efficient source of ignition and the anticipated effects of an explosion, entail the basic principles of prevention and protection against explosion.

In relation to the explosion hazard presumed by the classification by zones, technical equipment used in these zones must be eligible. This results in categories and levels of equipment protection.

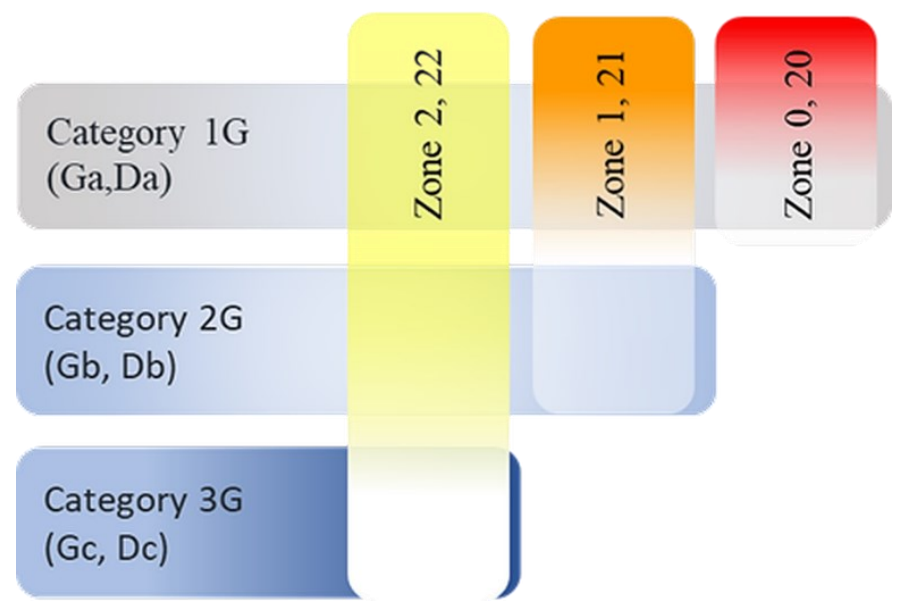

Fig. 1. Protection category / level - area correlation

\section{Opportunities to use pressurization}

The 'pressurization' or 'pressurized housing' protection method is based on maintaining a constant positive air pressure or a shielding gas inside the housing to prevent the possibility of an explosive mixture in the vicinity of components inside the pressurized housing.

In this way, a pressurized housing makes it possible to use equipment without explosion protection in zones $1,2,21$ and 22 .

A peculiarity of protection based on the principle of pressurization is that explosion protection is achieved only if the specific conditions of pressurization are met, and their monitoring and validation is performed by so-called safety devices. In addition, due to the fact that these safety devices are powered by electricity and operate even when the specific 
conditions of pressurization are not met, they must be explosion-proof in accordance with the requirements of hazardous atmospheres in which the pressurized housing is located.

Many production environments include explosive atmospheres caused by the presence of flammable gases, vapours, mists or dust. Standard equipment cannot be safely used here and it is often necessary to choose expensive, explosion-proof components. In many cases, the use of a pressurized housing provides an interesting alternative to be able to also use components that do not have explosion protection in hazardous areas.

Pressurized housings and their connecting components must be designed as to withstand the maximum pressure of the pressurisation or ventilation system and be designed in such a way as to minimize the ingress of flammable gases, flammable vapours and dust.

\section{Considerations regarding materials, gauge and shape of pressurized equipment}

The materials used for making the pressurized housing, pipes and connecting parts must not be adversely affected by the shielding gas [6].

Metallic materials used in the construction of electrical equipment housings [7] in Groups II and III for the identified levels of equipment protection shall not contain, by mass, more than:

- for EPL Ga: $10 \%$ in total of aluminium, magnesium, titanium and zirconium, and $7.5 \%$ in total of magnesium, titanium and zirconium;

- for EPL Da: $7.5 \%$ of total magnesium, titanium and zirconium;

- for EPL $\mathrm{Gb}$ and $\mathrm{Db}: 7.5 \%$ of total magnesium, titanium and zirconium;

- for EPL Gc and Dc: no requirements, except for those for blades and hoods for fans and ventilation screens, which must comply with the requirements for EPL Gb and $\mathrm{Db}$.

Non-metallic materials used in the construction of non-metallic carcases and non-metallic parts thereof shall have a mechanical "TI" or RTI temperature index, mechanically at least $20 \mathrm{~K}$ higher than the maximum working temperature of the housing or housing part.

Elastomeric materials must have a continuous operating temperature range that includes a minimum temperature that is below, or equal to, the minimum service temperature and a maximum temperature that is at least $20 \mathrm{~K}$ above the maximum service temperature. The equipment may have different operating temperatures on different parts of the equipment.

Plastics can be a source of electric shock if material strength exceeds $10^{9} \mathrm{ohms}$. The use of this type of plastic in equipment can induce dangerous situations in environments classified as Ex.

Compared to metal, plastics are cheaper, lighter and more resistant to corrosion.

The distribution diagram of material types used to make the pressurized housings within the analysed housing sample, highlights the preponderance of stainless steel in construction of housings, followed by far by aluminium and sheet steel. The presence of composite housings is also noticeable (Fig. 2). 


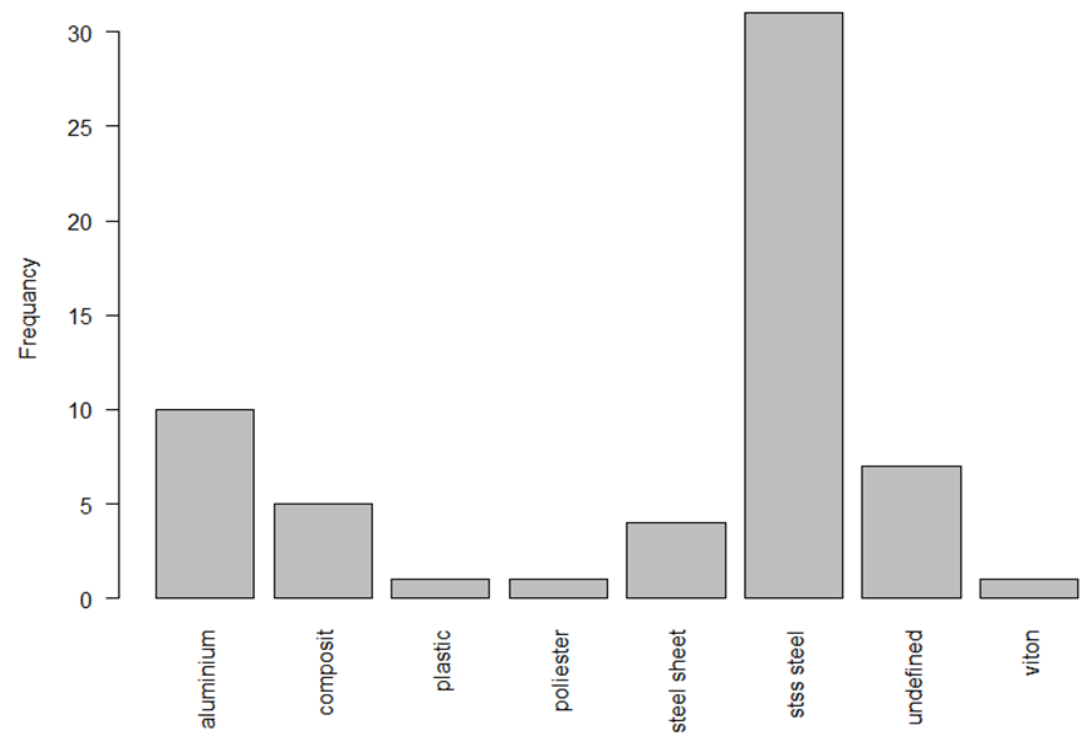

Fig. 2. Distribution of material types used for making pressurized housings within the analysed sample

Related to the shape of pressurized housings, the coefficients defined as the ratio height to width $(\mathrm{H} / \mathrm{W})$ and respectively, depth to width (D/W), in the distribution density diagram, highlight the preponderance of housings having a height half their width and a depth approximately equal to their width (Fig. 3).

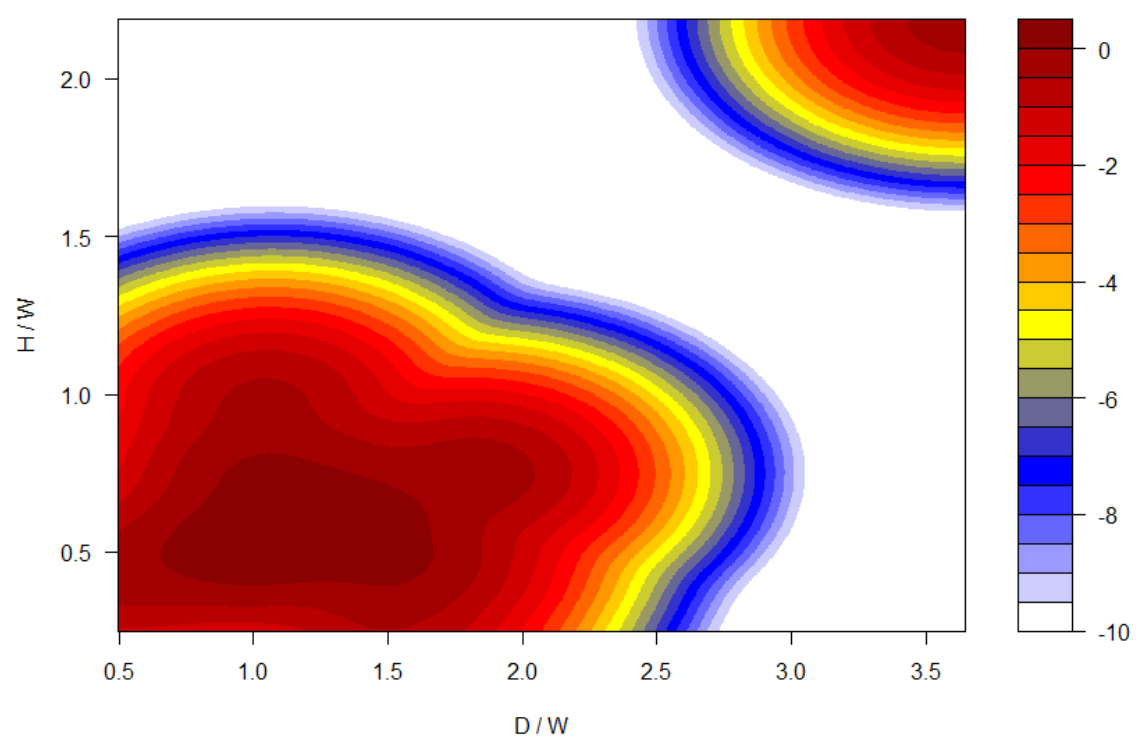

Fig. 3. Distribution density of the coefficients for the pressurized housings in the analysed sample

Analysis of depth value distribution for the sample of pressurized housings highlights the fact that most pressurized housings have a depth of up to $200 \mathrm{~mm}$, but there are also housings that have a depth between 500 and $600 \mathrm{~mm}$. Usually, pressurized housing protection 
is suitable for large equipment, but large equipment is made in unique construction, and smaller equipment is suitable for series production (Fig. 4).

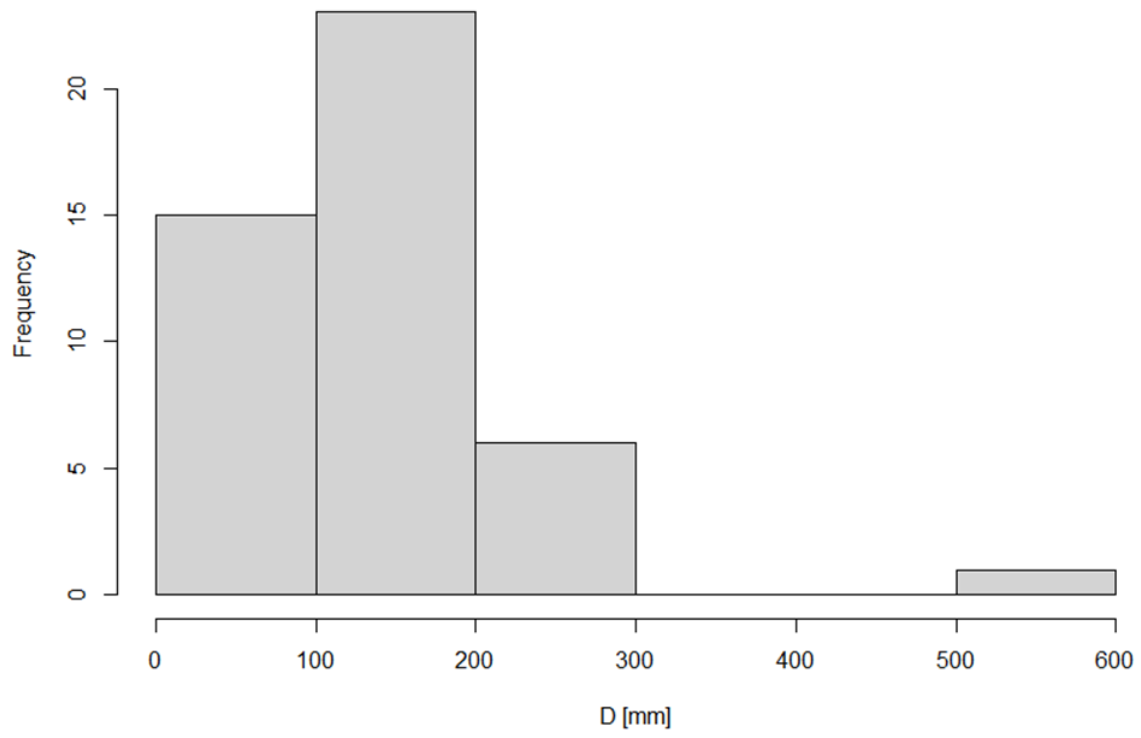

Fig. 4. Histogram of the depth value of pressurized housings within the analysed sample

Analysis of width value distribution for the sample of pressurized housings highlights the fact that most pressurized housings have a width between 100 and $300 \mathrm{~mm}$, but there are also housings that have a width of $1000 \mathrm{~mm}$ (Fig. 5).

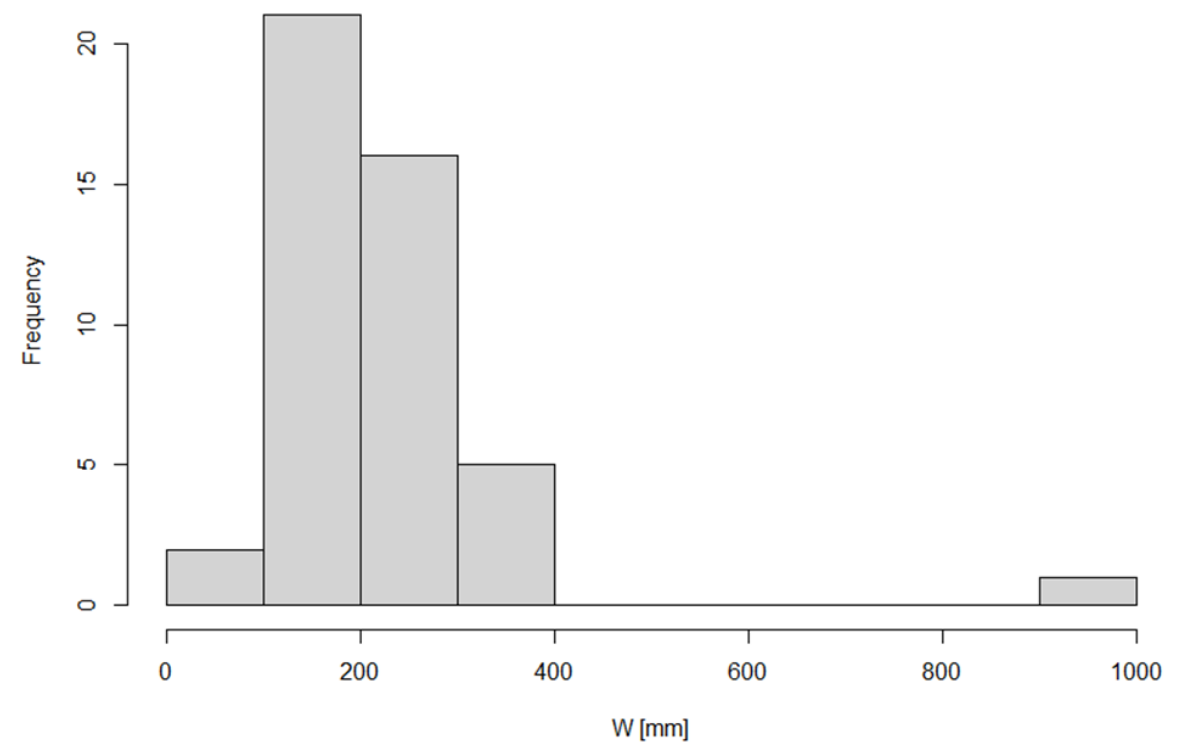

Fig. 5. Histogram of the width value of pressurized housings within the analysed sample 
Analysis of the distribution of height values for the sample of pressurized housings highlights the fact that most of the pressurized housings have a height of around $200 \mathrm{~mm}$, but there are also housings that have a width of $1000 \mathrm{~mm}$ (Fig. 6).

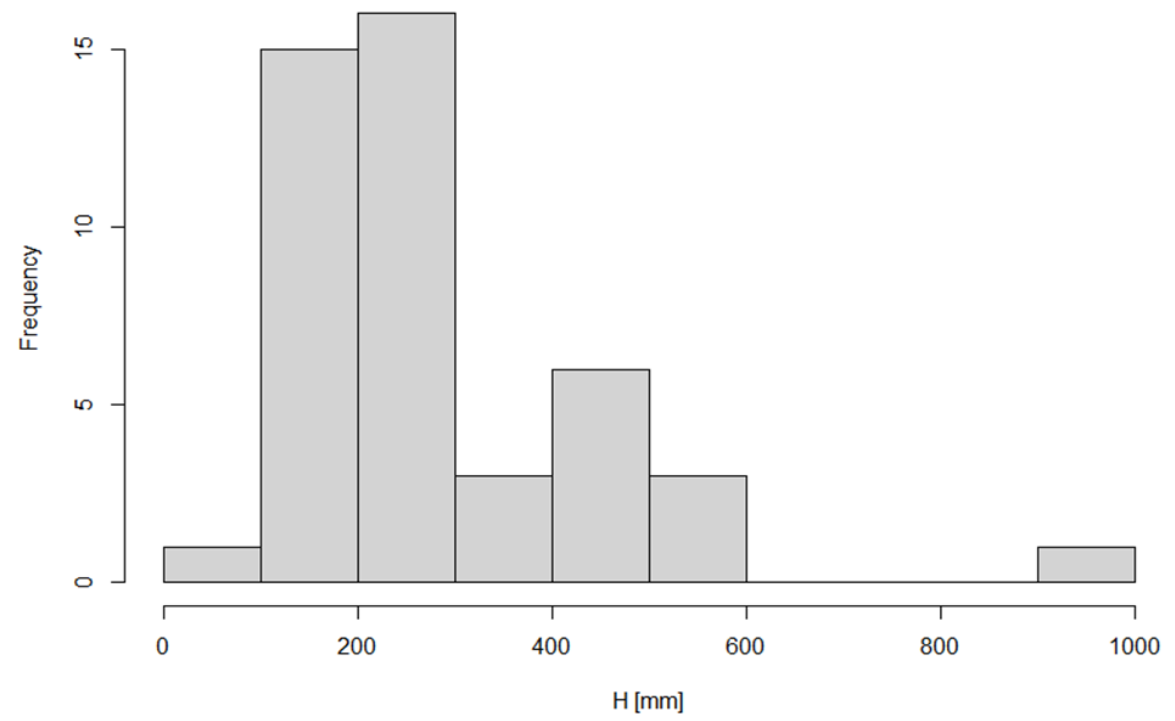

Fig. 6. Histogram of the height value of pressurized housings within the analysed sample

Analysis of the distribution of volume values for the sample of pressurized housings highlights the fact that most pressurized housings have a volume of around 10 litres, but there are also housings that have a volume of hundreds of litres (Fig. 7).

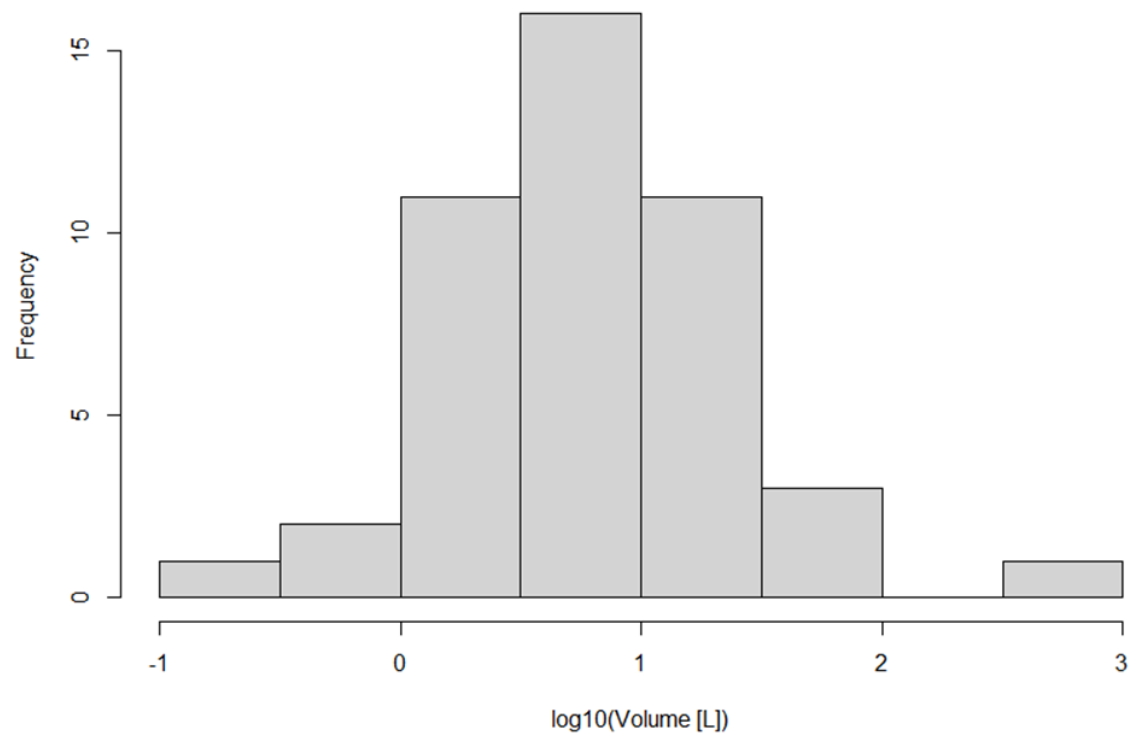

Fig. 7. Decimal logarithm histogram for volume value of pressurized housings within the analysed sample 
Analysis of zones distribution for the sample of pressurized housings highlights the fact that most of them are intended for use in zones 1, 2, 21 and 22 (Fig. 8).

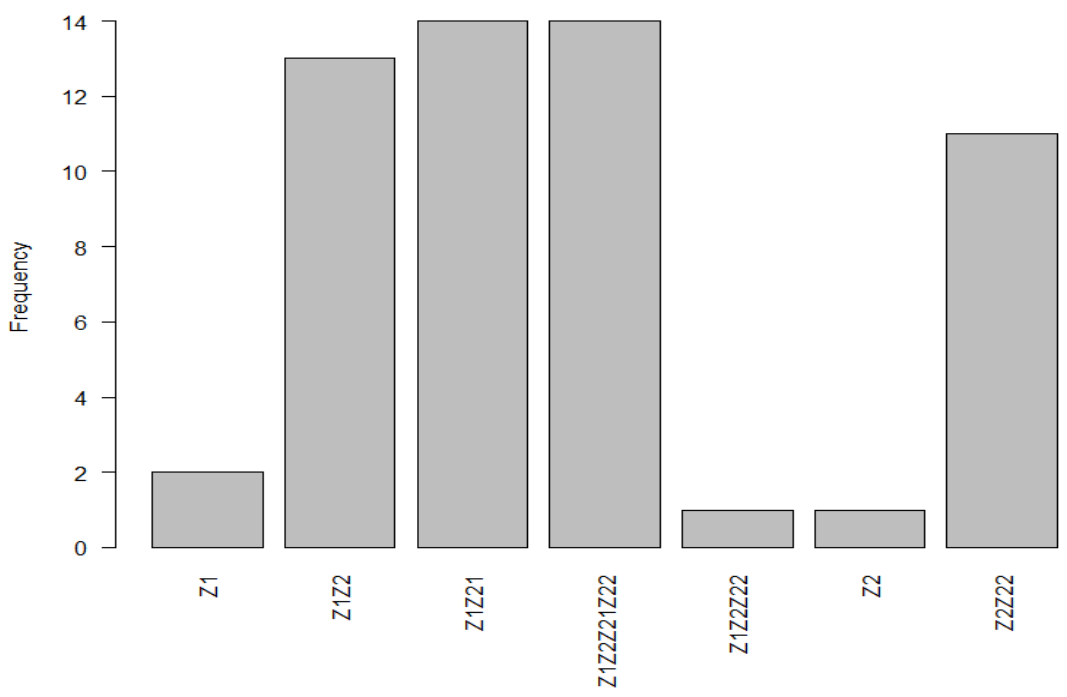

Fig. 8. Histogram of the areas for which the pressurized housings of the analysed sample are intended

\section{Conclusions}

In addition to other advantages offered by the use of pressurized housing protection, the possibility of protecting equipment intended for use in atmospheres with combustible dust can be highlighted.

Distribution diagram of material types used to make the pressurized housings within the analysed housings sample, highlights the preponderance of stainless steel in construction of housings, followed by far by aluminium and steel sheet. The presence of composite housings is also noticeable.

Regarding the shape of pressurized housings, preponderance of housings of having a height half their width and a depth approximately equal to their width is highlighted.

Analysis of depth value distribution for the sample of pressurized housings highlights the fact that most pressurized housings have a depth of up to $200 \mathrm{~mm}$, but there are also housings that have a depth between 500 and $600 \mathrm{~mm}$.

Analysis of width value distribution for the sample of pressurized housings highlights the fact that most pressurized housings have a width between 100 and $300 \mathrm{~mm}$, but there are also housings that have a width of $1000 \mathrm{~mm}$.

Analysis of the distribution of height values for the sample of pressurized housings highlights the fact that most of the pressurized housings have a height of around $200 \mathrm{~mm}$, but there are also housings that have a width of $1000 \mathrm{~mm}$.

Small pressurized equipment is suitable for standardization and is present on the market in various shapes and sizes, mainly those with a volume or capacity of around 10 litres.

Analysis of zones distribution for the sample of pressurized housings highlights the fact that most of them are intended for use in zones 1, 2, 21 and 22. 
The R language and the R Studio environment [8], [9] and [10] were used for calculating and ploting the diagrams. The readxl package was also used [11].

\section{References}

1. Ghicioi E., Vlasin N., Prodan M., Pasculescu V., Gabor D., Environ Eng Manag J, 16, 1290-1294, (2017)

2. Prodan M., Ghicioi E., Oancea D., Environ Eng Manag J, 13, 1409-1414, (2014)

3. Government Decision no. 1058 of August 9, 2006 on the minimum requirements for improving the safety and health protection of workers who may be exposed to a potential risk due to explosive atmospheres, 2006;

4. V. M. Pasculescu, N. I. Vlasin, E. Ghicioi, G. D. Florea, M.C. Suvar, Environ Eng Manag J, 18 (4), 889-900, (2019)

5. Directive 2014/34/EU (2014) - Equipment for potentially explosive atmospheres (ATEX), available https://ec.europa.eu/growth/sectors/mechanical-engineering/atex_en.

6. Standard EN 60079-2 (2014) - Explosive atmospheres - Part 2: Equipment protection by pressurized enclosure "p".

7. Standard EN IEC 60079-0 (2018) - Explosive atmospheres - Part 0: Equipment - General requirements.

8. R Development Core Team (2008). R: A language and environment for statistical computing. R Foundation for Statistical Computing, Vienna, Austria. ISBN 3-900051-07-0, URL http://www.Rproject.org.

9. R Core Team (2015). R: A language and environment for statistical computing. R Foundation for Statistical Computing, Vienna, Austria. URL http://www.R-project.org/.

10. Lionel Henry and Hadley Wickham (2020). rlang: Functions for Base Types and Core R and 'Tidyverse' Features. R package version 0.4.10. https://CRAN.R-project.org/package=rlang

11. Hadley Wickham and Jennifer Bryan (2019). readxl: Read Excel Files. R package version 1.3.1. https://CRAN.R-project.org/package=readxl 